\title{
REPRESENTAÇÕES SOCIAIS: SEU STATUS ONTOLÓGICO
}

SOCIAL REPRESENTATION: ITS ONTOLOGICAL STATUS

REPRESENTACIONES SOCIALES: SU STATUS ONTOLÓGICO

\author{
Elismar Alves dos Santos* \\ Pedrinho Arcides Guareschi**
}

\begin{abstract}
RESUMO
O status ontológico das representações sociais (RS) tem seus próprios fundamentos filosóficos, o que indica sua origem e identidade. Moscovici (1925-2014), idealizador da teoria das representaçôes sociais (TRS), recorreu a diferentes pensadores para demonstrar como se dá a formação das representações sociais nos seres humanos. Entre estes destacam-se Durkheim, Lévy-Bruhl, Piaget e Freud. Significa que o status ontológico das representações sociais encontra fundamentos nos aspectos sociológicos, antropológicos, cognitivos e psicanalíticos. $\mathrm{O}$ objetivo deste artigo consiste em mostrar como esses pensadores influenciaram na criação do status ontológico das representações sociais. Para alcançar essa finalidade, o estudo valeu-se do método dedutivo como base lógica de raciocínio, da pesquisa bibliográfica como técnica de investigação e realizaram-se diversas análises das obras, em diferentes etapas, pela utilização de fichas de documentação. A conclusão a que chegamos é que as representações sociais não são apenas ideias filosóficas, mas especialmente práticas vivenciais transmitidas por meio da comunicação.
\end{abstract}

Palavras-chave: Representações sociais. Representação. Moscovici. Ontologia.

\begin{abstract}
The ontological status of social representations (SR) has its own philosophical fundaments, which indicate its origin and identity. Moscovici (1925-2014), founder of the Social Representation Theory (SRT), turned to different thinkers to demonstrate how the formation of social representations in
\end{abstract}

\footnotetext{
Texto recebido em 4 de abril de 2016 e aprovado para publicação em 9 de outubro de 2017.

"Pós-doutor em Psicologia pela Pontifícia Universidade Católica de Goiás (PUC-GO); doutor em Psicologia Social e Institucional pela Universidade Federal de Rio Grande do Sul (UFRGS); doutor em Teologia Moral pela Faculdade Jesuíta de Filosofia e Teologia (Faje); com estágio na Universidad Pontificia Comillas, de Madrid, Espanha; mestre em Psicologia pela PUC-GO; licenciado em Filosofia; bacharel em Teologia; licenciado em Psicologia; professor de Psicologia e Teologia no Instituto de Filosofia e Teologia de Goiás (Ifiteg) e na PUC-GO. E-mail: elismar01@yahoo.com.br.

"* Pós-doutor na University of Wisconsin, EUA, e na Universidade de Cambridge, Inglaterra; doutor em Psicologia Social na Universidade de Wiscosin at Medison, EUA; mestre em Psicologia Social na Marquete University, EUA; licenciado em Filosofia; bacharel em Teologia; licenciado em Letras; pós-graduado em Sociologia pela Pontifícia Universidade Católica do Rio Grande do Sul (PUC-RS); professor e pesquisador no Programa de Pós-Graduação em Psicologia Social e Institucional da UFRGS; pesquisador do CNPQ. E-mail: pedrinho.guareschi@ufrgs.br.
} 
humans is. Among them are: Durkheim, Lévy-Bruhl, Piaget and Freud. It means that the ontological status of social representations are grounded on sociological, anthropological, cognitive and psychoanalytical aspects. The aim of this article is to show how these thinkers have influenced the creation of the ontological status of social representations. In order to achieve this goal, the present study was based on the deductive method as a logical basis for reasoning, bibliographical research as a technique and several analyzes of the works were carried out, at different stages, using documentation sheets. The conclusion we have come to is that social representations are not only philosophical ideas, but are, especially, living practices broadcast by communication.

Keywords: Social representations. Representation. Moscovici. Ontology.

\section{RESUMEN}

El status ontológico de las Representaciones Sociales (RS) tiene sus propios fundamentos filosóficos, que indican su origen e identidad. El idealizador de la Teoría de las Representaciones Sociales (TRS), Moscovici (1925 - 2014), al exponer cómo se forman las representaciones sociales en los seres humanos, se remite a diferentes pensadores, entre ellos Durkheim, Lévy-Bruhl, Piaget y Freud. Esto significa que el status ontológico de las representaciones sociales encuentra fundamentos en los aspectos sociológicos, antropológicos, cognitivos y psicológicos. Este artículo propone demostrar cómo determinados pensadores influyeron en la creación del status ontológico de las representaciones sociales. Para alcanzar su objetivo fue utilizado el método deductivo como base lógica del razonamiento y de la pesquisa bibliográfica como técnica de investigación. También, en diferentes etapas, fueron realizados diversos análisis de obras, utilizando hojas de documentación. La conclusión obtenida es que las representaciones sociales no solo son ideas filosóficas, sino, especialmente, prácticas existenciales transmitidas a través de la comunicación.

Palabras clave: Representaciones sociales. Representación. Moscovici. Ontología.

\section{INTRODUÇÃO}

o falar em Teoria das Representações Sociais (TRS), é preciso estar atento
à seguinte observação:

A grande teoria das representações sociais - como chamamos (Sá, 1996) as proposições originais básicas de Moscovici - desdobra-se em três correntes teóricas complementares: uma mais fiel à teoria original, liderada por Denise Jodelet, em Paris; uma que procura 
articulá-la com uma perspectiva mais sociológica, liderada por Willem Doise, em Genebra; uma que enfatiza a dimensão cognitiva-estrutural das representações, liderada por JeanClaude Abric, em Aix-en-Provance (Sá, 1998, p. 65).

As representações sociais, no vasto universo da Psicologia, procuram olhar para esta de uma forma re-humanizada. Colocam-nos dentro de nosso contexto, mergulham-nos na história e buscam a compreensão dos significados que nos fornecem informações com as quais retrabalhamos a realidade.

O objetivo principal deste artigo consiste em apresentar como alguns estudiosos, entre eles Durkheim, Lévy-Bruhl, Piaget e Freud, influenciaram na criação do status ontológico das representações sociais. Para alcançar esse objetivo, nós nos valemos da dedução como método lógico de raciocínio (Gil, 2011) e da técnica de pesquisa bibliográfica (Severino, 2002, p. 38), em que percorremos o seguinte caminho:

a) delimitação da unidade de leitura;

b) análise textual;

c) análise temática;

d) análise interpretativa; e

e) problematização (Severino, 2002, pp. 51-58).

Como instrumentos, utilizamos fichas de documentação bibliográficas de informação geral, resumo e citações (Marconi \& Lakatos, 2011).

A relevância do artigo consiste na explanação do caminho epistemológico realizado por Moscovici, conforme já dito, por meio de uma revisão bibliográfica de algumas de suas obras e de outros autores consultados por este. Com base nesses autores, Moscovici construiu filosoficamente sua própria compreensão de representação social, deixando uma importante contribuição para a Psicologia Social.

O artigo está organizado em três partes. A primeira esclarece brevemente o que se entende por metafísica ou ontologia. A segunda parte, por sua vez, descreve em qual status ontológico estão fundamentadas as representações sociais. Por último, na terceira parte, discute-se: o que dizer sobre a dimensão ontológica das representaçóes sociais? Moscovici ressalta que o status ontológico das representações sociais pode ser identificado com base na História e na 
Antropologia. Daí seu dizer de que as representações sociais são realmente entidades sociais.

\section{METAFÍSICA OU ONTOLOGIA}

Metafísica ou ontologia são termos originários da filosofia de Aristóteles (2006). O título da obra de Aristóteles é justamente este: Metafísica. Título não formulado pelo filósofo grego, mas por quem organizou seus escritos após sua morte. A ontologia ou metafísica, nos escritos de Aristóteles (2006), são as reflexões que vêm após as obras dedicadas à Física, por isso "Meta-Física". A metafísica, como foi entendida e projetada por Aristóteles, "É a ciência primeira no sentido que fornece a todas as outras o fundamento comum, isto é, objeto ao qual todos se referem e os princípios dos quais todas dependem" (Abbagnano, 1982, p. 633). Na Metafísica de Aristóteles, é possível encontrar, precisamente nos livros VII, VIII, IX, a compreensão da metafísica como teoria da substância, entendendo-se por substância "aquilo que um ser não pode deixar de ser" (Aristóteles, 2006, pp. 177-225; 227). Entretanto, a metafísica é, na verdade, uma ontologia ou doutrina que estuda os caracteres fundamentais do Ser: aqueles caracteres que todo ser possui e não pode deixar de possuir (Abbagnano, 1982, p. 635). Desse modo, a metafísica ou ontologia seria a área responsável pelo estudo do Ser. Aliás, não somente do Ser, mas também do Ente. Isso porque “Ontos", em grego, é "Ser".

\section{STATUS ONTOLÓGICO QUE FUNDAMENTA AS REPRESENTAÇÕES SOCIAIS}

A TRS sofreu várias influências de distintos teóricos de diferentes áreas do conhecimento. É a partir da compreensão de sua origem que se torna possível entender mais claramente o que significa afirmar que as representações sociais têm uma base ontológica. Essa base ontológica não é outra coisa senão o status filosófico que a sustenta. É de conhecimento que Moscovici (2009) recorreu a diferentes pensadores em vista de construir filosoficamente sua própria compreensão de representação social. Entre esses pensadores, destacam-se Durkheim, Lévy-Bruhl, Piaget e Freud. Desejamos descrever sinteticamente como esses pensadores influenciaram na construção filosófica e prática da TRS.

Na obra Representaçôes sociais: investigaçôes em Psicologia Social, Moscovici (2009) deixa clara a influência de Durkheim na elaboração de seu conceito de representações sociais. Assim escreve: "É óbvio que o conceito de representações sociais chegou até nós vindo de Durkheim. Mas nós temos uma visão diferente 
dele - ou de qualquer modo, a Psicologia social deve considerá-lo de um ângulo diferente - de como faz a sociologia” (Moscovici, 2009, p. 45). Para Durkheim (2003), as representaçōes sociais são coletivas. Tais representações estão relacionadas com as crenças, sentimentos e ideias que são preestabelecidas, compartilhadas e vividas sem discussão e interrogações em uma determinada comunidade. Assim escreve Durkheim (2003) em sua monumental obra As formas elementares da vida religiosa:

Se é comum a todos é porque é obra da comunidade. Já que não traz a marca de nenhuma inteligência particular, é porque é elaborado por uma inteligência única, onde todas as outras se reúnem e vêm, de certa forma, alimentar-se. Se ele tem mais estabilidade que as sensaçōes ou as imagens é porque as representaçôes coletivas são mais estáveis que as individuais, pois, enquanto o indivíduo é sensível até mesmo a pequenas mudanças que se produzem em seu meio interno ou externo, só eventos suficientemente graves conseguem afetar o equilíbrio mental da sociedade (Durkheim, 2003, p. 603).

As representações coletivas referem-se precisamente a isto: às crenças, sentimentos e ideias habituais, dadas e homogeneamente compartilhadas de uma comunidade.

Elas são preestabelecidas em relação a indivíduos (pela tradição, costumes e história) e aceitas sem discussão; elas sobrepujam a consciência individual e sustentam o enquadre moral que guia a ação de todos os membros de uma comunidade (Jovchelovitch, 2011, p. 97).

As representações coletivas, como descreve Durkheim (2003), de acordo com Moscovici (2001, p. 47), pertencem a "uma ampla classe de formas mentais (ciências, religiões, mitos, espaço, tempo), de opiniões e de saberes sem distinção". O mito, por exemplo, para Durkheim, "É um fenômeno cultural estratificado, cristalizado, não possui a dinamicidade e a historicidade que se quer dar ao conceito de representação social" (Guareschi, 1996, p. 24). Segundo Moscovici (2009), a visão de Durkheim (2003) sobre o modo como operam e agem essas representaçôes coletivas mostra que elas são estáticas.

Durkheim, fiel à tradição aristotélica e kantiana, possui uma concepção bastante estática dessas representaçôes - algo parecido com a dos estoicos. Como consequência, representaçôes em sua teoria, são como adensamento da neblina, ou, em outras palavras, elas agem como suportes para muitas palavras ou ideias - como as camadas de um ar estagnado na atmosfera da sociedade, do qual se diz que pode ser cortado com uma faca (Moscovici, 2009, p. 47).

O interesse de Moscovici (2009) não está centrado propriamente nas representações coletivas de Durkheim (2003). Essas, em sua concepção, são estáticas, partilhadas e reproduzidas de modo coletivo. Em geral, continua 
Moscovici (2001, p. 47), "Durkheim opõe as representações coletivas às representações individuais por meio de um mesmo critério, a saber: a estabilidade da transmissão e da reprodução de algumas; a variabilidade ou o caráter efêmero das outras". E, de maneira mais precisa, ainda pontua o que se entende por representações coletivas:

Compreende-se que tal representação seja homogênea e vivida por todos os membros de um grupo, da mesma forma que partilham uma língua. Ela tem por função preservar o vínculo entre eles, prepará-los para pensar e agir de modo uniforme. Ela é coletiva por isso e também porque perdura pelas geraçôes e exerce uma coerção sobre os indivíduos, traço comum a todos os fatos sociais (Moscovici, 2001, p. 47).

A citação a seguir mostra que tipo de representação interessa a Moscovici (2009) e, ao mesmo tempo, evidencia a sua distância em relação ao significado das representações coletivas de Durkheim (2003).

As representações sociais que me interessam não são nem as das sociedades primitivas, nem as suas sobreviventes, no subsolo de nossa cultura, dos tempos pré-históricos. Elas são as de nossa sociedade atual, de nosso solo político, científico, humano, que nem sempre têm tempo suficiente para se sedimentar completamente para se tornarem tradições imutáveis (Moscovici, 2009, p. 48).

Não há dúvida de que o primeiro tipo de representação corresponde às representações coletivas de Durkheim (2003). É daí que Moscovici (2009) retira a inspiração para elaborar o seu próprio conceito de representaçôes sociais. Guareschi (2011) faz um excelente resumo quanto à intenção de Moscovici (2009) em substituir as representações coletivas de Durkheim (2003) pelas representaçóes sociais. "Moscovici tinha consciência que o modelo de sociedade de Durkheim era estático e tradicional, pensado para tempos em que a mudança se processava lentamente" (Guareschi, 2011, p. 157). Ao passo que, continua o autor supracitado, "As sociedades modernas, porém, são dinâmicas e fluidas. Por isso o conceito de 'coletivo' apropriava-se melhor àquele tipo de sociedade, de dimensões mais cristalizadas e estruturadas". Segundo o autor da citação, "Moscovici preferiu preservar o conceito de representação e substituir o conceito 'coletivo', de conotação mais cultural, estática e positiva, como o de 'social': daí o conceito de Representações Sociais" (Guareschi, 2011, p. 157).

Entretanto é bom lembrar, como ressalta Marková (2006), que a separação feita por Durkheim (2003) sobre o individual e o social foi um passo importante no desenvolvimento da Psicologia e das Ciências Sociais. Especificamente para as representações sociais, lembra a autora, "Foi somente após a Segunda Guerra 
Mundial, durante os anos 50 e 60, que o conceito da representação coletiva e social foi re-instituído nos estudos sociais psicológicos de Serge Moscovici” (Marková, 2006, p. 187).

É nesse contexto, como ressaltado por Guareschi (2011), que Moscovici (2009) sublinha que, em decorrência das rápidas transformações que a sociedade vive, as representações são mais facilmente transformáveis e mutáveis. Assim, para Moscovici (2001), as representaçôes sociais não são estáticas a exemplo das representações coletivas de Durkheim (2003). Ao contrário, são dinâmicas, isto é, não seriam de outra natureza senão pertencentes aos grupos sociais que as criam. As representaçōes sociais, diferentemente das representaçōes coletivas do sociólogo francês, são tanto práticas como simbólicas. E como práticas e simbólicas, não se originam somente em uma única sociedade, mas nas diversas sociedades que existem universalmente falando. Por isso o senso comum será, para Moscovici (2009), uma forma de mostrar que as representaçôes sociais se encontram nas realidades do dia a dia na vida das pessoas e nos distintos grupos sociais. Certamente, um dos teóricos adotados para mostrar o alcance do significado do senso comum para as representaçôes sociais foi Lévy-Bruhl.

Vejamos, assim, no que consistiriam as contribuições de Lévy-Bruhl ao status ontológico das representaçóes sociais. De acordo com Moscovici (2001, p. 51), "Por meio da tessitura psíquica e da configuração mental que as cimenta, LévyBruhl descobre a coerência dos sentimentos e dos raciocínios, os movimentos da vida mental coletiva”. Recorda que, para Lévy-Bruhl, numa mesma sociedade, há diferentes tipos de saberes. Essa afirmação pode ser resumida pela seguinte formulação: "Lévy-Bruhl, como a maioria de seus contemporâneos, começou perguntando-se se é correto pensar que a mente humana é a mesma em todo lugar" (Jovchelovitch, 2011, p. 100). Moscovici (2009) ressalta que Lévy-Bruhl "tentou mostrar que se as representações são racionais aos olhos dos membros de uma cultura, elas necessitam ser assim tanto no mesmo sentido, ou de acordo com a mesma lógica, aos olhos de outra cultura" (Moscovici, 2009, p. 289). Assim, de acordo com os estudiosos, "a partir de seus estudos sobre a mente primitiva, Lévy-Bruhl estabeleceu algumas características fundamentais das representações coletivas encontradas predominantemente em sociedades tradicionais" (Jovchelovitch, 2011, p. 101). A partir dessas descobertas, os estudiosos dizem que não há dúvida de que foi em Lévy-Bruhl que Moscovici (2009) se inspirou para compreender a dinâmica das representações sociais. Tacitamente, Lévy-Bruhl "insistiu no fato de que diferentes tipos de saberes estão presentes na mesma sociedade, rejeitando assim a ideia de uma correspondência entre o primitivo e o pré-lógico e entre o desenvolvido e o lógico" (Jovchelovitch, 2011, p. 105). 
O alcance das descobertas de Lévy-Bruhl possibilitou a Moscovici (2009) pensar a respeito dos elementos de produção das representações sociais. Como se constrói um tipo de saber e como ele se relaciona a outras formas de saber? O legado de Lévy-Bruhl para a construção da TRS pode ser sintetizado a partir deste dizer: "O que a teoria das representações sociais faz é colocar na pauta também o conhecimento popular, as maneiras de pensar e agir na vida cotidiana, o senso comum, se quisermos, que fazem parte de um universo consensual" (Guareschi, 2007, p. 34). Lévy-Bruhl contribui decisivamente para mostrar que há uma diversidade de saberes na sociedade. Com isso, o antropólogo francês inspirou Moscovici (2012, p. 328) a construir o conceito de polifasia cognitiva. "O pensamento social é constituído de uma pluralidade de modos de reflexão que um indivíduo utiliza em função dos seus objetivos e do domínio que ele possui sobre o meio-ambiente onde se encontra inserido" (Nóbrega, 2003, pp. 72-73).

Para concluir essa parte, recorro mais uma vez à autora supracitada para deixar mais claro o conceito de polifasia. "A polifasia cognitiva revela as diferentes formas de reflexão e os ordenamentos do raciocínio confrontados às relações definidas do homem com sua cultura" (Nóbrega, 2003, p. 73). Significa que, numa mesma cultura, pode haver distintas representaçôes sociais devido à diversidade de saberes.

$\mathrm{Na}$ sequência do estudo dos teóricos que influenciaram no status ontológico das representações sociais de Moscovici (2009), encontra-se Piaget, especialmente no que se refere às suas descobertas relacionadas ao caráter construtivo da representação no processo de desenvolvimento da criança. Moscovici (2009, pp. 286-289) dedica parte de sua monumental obra, Representaçôes sociais: investigaçôes em Psicologia Social, ao estudo em forma de paralelo entre Piaget e Vygotsky. Segundo Moscovici (2009), Piaget optou pelo caminho indicado por Durkheim no sentido de observar que há uma evolução nas formas de representação. Entretanto Vygotsky, em decorrência de sua não adesão ao marxismo soviético daquela época, preferiu seguir Lévy-Bruhl, que dizia que uma mesma cultura pode gerar distintas representações. Assim, de Piaget e Vygotsky, Moscovici (2009, p. 289) recolheu os elementos necessários para falar da cognição no universo das representaçõos sociais. Vejamos o que diz o próprio Moscovici (2001, p. 53) em relação a Piaget. "O psicólogo suíço parte do postulado de que a criança não é mais 'boba', nem se encontra alguns degraus abaixo da criança mais velha. Contudo, ela pensa as coisas de modo essencialmente diferente". Ao se deparar com as descobertas de Piaget, Moscovici (2001; 2009) encontrou pistas que indicavam como as representaçôes sociais desenvolvem-se não somente a partir do universo cognitivo das crianças, mas descobriu também que essas mesmas 
representações fazem parte do universo dos adultos. Ora, se a criança é capaz de representar com base em seu próprio contexto, o mesmo pode-se aplicar ao adulto.

Desse modo, escreve Moscovici (2001, p. 54), Piaget "lega-nos uma análise que estabelece a especificidade das representações em termos psíquicos”. Nesse contexto, "Da Psicologia de Piaget, portanto, Moscovici retirou dimensões centrais de sua psicologia social: a conceituação de representação, a investigação do senso comum, a preocupação com mudança e desenvolvimento" (Jovchelovitch, 2011, p. 106). Piaget (2007), em sua obra Epistemologia genética, explica que a epistemologia genética aplicada à evolução do pensamento da criança, no nível do conhecimento, mostrou que:

Todo conhecimento contém um aspecto de elaboração nova, e o grande problema da epistemologia consiste em conciliar essa criação de novidades com o fato duplo de que, no terreno formal, elas se fazem acompanhar de necessidades imediatamente elaboradas, e de que, no plano do real, permitem (e são, de fato, as únicas a permitir) a conquista da objetividade (Piaget, 2007, p. 1).

É nesse sentido que se pode falar que Piaget (2007, pp. 7-47) formulou a psicogênese dos conhecimentos: os níveis sensório-motores; o primeiro nível do pensamento pré-operatório; o segundo nível pré-operatório; o primeiro nível do estágio das operações "concretas"; o segundo nível das operações "concretas"; e as operaçoos "formais". Não há o interesse aqui em explicar cada uma dessas etapas da psicogênese do conhecimento de Piaget (2007). Basta apenas pontuar, como ele mesmo escreve, que "a vantagem de um estudo do desenvolvimento dos conhecimentos que remonta às suas raízes consiste em fornecer uma resposta à questão mal resolvida da direção dos processos cognitivos iniciais" (Piaget, 2007, p. 7). A pesquisa de Piaget (2007) sobre o desenvolvimento do pensamento representacional na criança estabeleceu a especificidade das representações em termos psíquicos, pôs em evidência a centralidade da ação (esquemas sensóriomotores) no desenvolvimento do pensamento representacional e clarificou a gênese e os processos de transformação das representações simbólicas (Jovchelovitch, 2011, p. 106). Pelas descobertas de Piaget, Moscovici (2009, pp. 286-289) encontrou a noção de representação plenamente elaborada como uma ideia teórica. "O estudo do senso comum por meio da investigação das representações sociais é análogo aos estudos que Piaget realizou sobre a concepção de mundo da criança" (Jovchelovitch, 2011, p. 106). Assim, continua a autora, "Da Psicologia de Piaget, portanto, Moscovici retirou dimensões centrais de sua psicologia social: a conceituação de representação, investigação do senso comum, a preocupação com mudanças e desenvolvimento". 
A conceituação de representação com base no significado do senso comum, o que inclui a preocupação com as mudanças no processo de desenvolvimento da criança, mostra que a "teoria do equilíbrio psicossocial" de Piaget (1994) contribuiu essencialmente para ilustrar a constituição do juízo moral da criança. As descobertas do biólogo suíço revelaram que sua teoria assume uma compreensão da ontogênese do sentido moral. Essa compreensão baseia-se no princípio do equilíbrio psicossocial.

Segundo Piaget (1994), a moral infantil esclarece, num certo sentido, a moral do adulto. "Ao lado das representações do mundo, Piaget explorou o amplo domínio das representaçôes ou dos julgamentos morais e permanece fiel às convicções de Durkheim, relativas à sua natureza social e mesmo à sua própria estrutura" (Moscovici, 2001, p. 54). Para os estudiosos das representaçôes sociais, "a abrangência do esquema conceitual desenvolvido por Piaget para dar conta da ontogênese e da sociogênese das representaçôes ofereceu a Moscovici postulados centrais para produzir uma psicologia social do saber" (Jovchelovitch, 2011, p. 107).

De acordo com a autora, é possível identificar duas inspirações das descobertas de Piaget que foram essenciais para as representações sociais de Moscovici (2009). Primeiramente, por meio de um escrito de Piaget: A representação do mundo na criança (1929, apud Moscovici, 2009). Nesse livro, Piaget investigou o conteúdo e a lógica subjacentes ao mundo da criança por meio de uma investigação das "teorias" que a criança constrói sobre o próprio pensamento, o nomear e o sonhar, a vida, as origens do Sol e da Lua, o céu, as nuvens, a explicação da noite, do gelo, da neve, dos rios, lagos e mar, as origens das árvores, montanhas e da terra (Jovchelovitch, 2011, p. 107). Em segundo, outra dimensão da obra de Piaget que está no centro das representações sociais é o problema da transformação do saber, pois "a teoria das representaçóes sociais é uma teoria de como o conhecimento é transformado e se move de uma forma estrutural a outra" (Jovchelovitch, 2011, p. 107). A concepção de mundo da criança, como organizou Piaget $(1994 ; 2007)$, retrata justamente o modo simples e criativo como elas percebem as coisas e como se veem nesse processo de interação. Daí que a transformação do saber é, para as representações sociais, um elemento indispensável para mostrar como crianças e adultos constroem suas próprias representações. Por isso, "não podemos entender o conceito de representação social sem darmos uma olhada no conhecimento de senso comum" (Marková, 2006, p. 191).

Vejamos, nesse momento, em que consistiriam as contribuições de Freud à elaboração das representações sociais. Da extensa produção de Freud 
$(1905 / 1996)^{1}$, Moscovici $(2001 ; 2009)$ retirou dois temas considerados essenciais para a compreensão da base ontológica das representações sociais: o inconsciente e as teorias sexuais infantis. "Em Freud, Moscovici encontrou os recursos para entender os processos inconscientes que configuram a produção dos saberes sociais e uma visão de conhecimento que não tem medo de se engajar com o psicológico propriamente dito" (Jovchelovitch, 2011, p. 115). Para a psicanálise freudiana, os processos psíquicos são, em si mesmos, inconscientes e por isso eles indicam e apontam para o significado do simbólico.

Daí a efervescência das representações da primeira infância que, pouco a pouco, deslizam, reprimidas, para o inconsciente, enquanto outras se formam, diferentes, mais intelectuais e severas, relativamente ao problema dos sexos, sob a ação da educação (Moscovici, 2001, p. 58).

As descobertas na área da sexualidade infantil nos escritos de Freud (1905) serviram de fonte de inspiração à Psicologia do Saber, de Moscovici (2009). Ele faz referência aos Três ensaios sobre a teoria da sexualidade de Freud (1905, pp. 128-229). Freud, na mencionada obra, especialmente, em Segundo ensaio: a sexualidade infantil, coloca em discussão a forma como as crianças constroem a "teoria" da sexualidade. Essas construções "se originam no ambiente cultural, nas lendas e contos de fadas. Ele discute o desejo de saber da criança e sua ligação com os ritos dos que desejam saber e dos que detêm o saber" (Jovchelovitch, 2011, pp. 115-116). Assim, Freud (1905) mostrou que as emoções sexuais têm uma parte importante nas criaçóes do espírito humano nos campos da cultura, da arte e da vida social (Rey, 2012). É nesse sentido, então, que se poderia falar que Moscovici $(2001 ; 2009)$ reconhece a importância dos Três ensaios sobre a teoria da sexualidade, de Freud (1905), especialmente na parte dedicada à sexualidade infantil para as representações sociais.

Mais pertinentes ainda são os estudos sobre as teorias sexuais da criança (Freud, 1908), que também suscitaram meu interesse. Nesse pequeno texto, Freud reúne diversos materiais fornecidos pelas crianças e pelos relatos dos pais. Reconhece sua origem na cultura circundante, entre contos e lendas. Ao mesmo tempo, mostra que as crianças criam essas teorias com elementos provenientes dessa cultura, para responder às questốes de sua vida imediata: "De onde vêm os bebês? De onde veio esse bebê particular, esse intruso?" (Moscovici, 2001, p. 56).

As crianças são constantemente estimuladas pela curiosidade sexual de seus pais e incomodadas diante do mistério do nascimento dos bebês. São movidas pelo desejo a encontrar soluçôes a tais indagaçôes.

1 A primeira data indica o ano de publicação da obra, e a segunda, a edição consultada pelo autor, a qual somente será pontuada na primeira citação da obra no texto. Nas seguintes, será registrada apenas a data de publicação original. 
Daí o caráter intenso, social e apaixonado das representaçôes da primeira infância; daí a compreensão de que o saber implica, ao mesmo tempo, desejo e luta; e aí a evidência de que essas primeiras batalhas moldam a maneira radical pela qual a gramática de uma cultura penetra a ontologia do saber, e em consequência, a ontologia do sujeito do saber (Jovchelovitch, 2011, p. 116).

Nesse sentido da ontologia do saber, Moscovici (2009) explica que seguramente a família é a célula em que isso se produz e se reproduz, inclusive o conflito psíquico. Especialmente, as interpretaçôes dos pais e as interrogações das crianças, entre a censura de uns e a liberdade dos outros. E completa: "Nesse sentido, as teorias sexuais das crianças têm igualmente um caráter social, sendo extraídas de um diálogo relançado pelo desejo do espectador e pela astúcia dos atores" (Moscovici, 2001, p. 58). Assim, para Moscovici (2001; 2009), as descobertas de Freud (1905) na área da sexualidade infantil levantam algumas questôes relevantes: "Como a representação do mundo da criança se torna representação do mundo do adolescente e depois do adulto? Quais são as etapas de semelhança e intelectualização das perguntas e das respostas?" (Moscovici, 2001, p. 58). Segundo a análise de Moscovici (2001), Freud (1905) apresenta um resumo das transações responsáveis pela origem das representações sexuais numa população, a partir das perguntas que as crianças fazem a seus pais, das observações feitas por elas dos esquemas de pensamento transmitidos pelos pais.

A Antropologia e a Psicologia da criança visam a uma comparação e a uma genealogia das formas cognitivas, indo do pensamento mítico ao pensamento científico, do conhecimento folclórico ao conhecimento racional, ou do pensamento operatório concreto ao pensamento operatório formal (Moscovici, 2001, p. 61).

Já estamos caminhando para o final da reflexão da segunda parte do artigo. Procuramos, então, mostrar as influências de alguns pensadores discutidos por nós na elaboração das representações sociais de Moscovici (2009). É possível encontrar, nos quatros teóricos estudados (Durkheim, Lévy-Bruhl, Piaget e Freud), que serviram de inspiração à criação do status ontológico das representações sociais de Moscovici (2009), um ponto que converge numa mesma direção: a valorização do senso comum como forma de saber. Especificamente sobre essa afirmação em relação a Freud, Moscovici (2001) deixa registrado com as seguintes palavras:

Muito frequentemente, os materiais reunidos por Freud pertencem ao senso comum, estando esparsos nos provérbios, lendas e relatos relativamente espalhados pela Europa pré-industrial. Nisso, mas não unicamente por isso, as teorias sexuais das crianças são representaçōes partilhadas (p. 57). 
Além dessa observação, a sexualidade é uma construção mental como objeto da experiência das crianças, o que se estende até a vida adulta. Sobre o legado freudiano para as representações sociais, encerramos por aqui.

Para compreender o que é designado por representações sociais, é necessário esclarecer o termo "representação" dentro da TRS. Com essa intenção, partindo de Piaget, Freud e Winnicott, Jovchelovitch (2011, pp. 62-70) mostra como se dá a construção genética do saber ao longo do desenvolvimento do ser humano. A criança, segundo a autora, em seu desenvolvimento, é marcada pelo contato com o mundo e as pessoas. O primeiro "outro" é a própria mãe ou alguém responsável pelo cuidado da criança. Em seguida, a criança precisa aprender a lidar com realidades concretas, ou seja, o mundo externo por meio dos objetos. Lentamente vai ocorrendo o processo de interação, cuja finalidade consiste na construção de um campo representacional (psíquico). Esse campo representacional é uma forma de saber (conhecimento). Significa que "representação" se trata de uma realidade própria, uma construção de saberes por meio de experiências a que o ser humano vai se submetendo ao longo da vida.

\title{
4. DIMENSÃO ONTOLÓGICA DAS REPRESENTAÇÕES SOCIAIS
}

O que desejamos realmente dizer ao propor uma reflexão sobre a dimensão ontológica das representaçôes sociais? Em Representaçôes sociais: investigaçôes em Psicologia Social, encontra-se, talvez, um dos dizeres de Moscovici (2009) que mais expressivamente evidencia o caráter ontológico das representações sociais.

\begin{abstract}
À luz da história e da antropologia, podemos afirmar que essas representaçōes são entidades sociais, com uma vida própria, comunicando-se entre elas, opondo-se mutuamente e mudando em harmonia com o curso da vida; esvaindo-se apenas para emergir novamente sob novas aparências. Geralmente, em civilizaçōes tão divididas e mutáveis como a nossa, elas coexistem e circulam através de várias esferas de atividade, onde uma delas terá precedência, como resposta à nossa necessidade de certa coerência, quando nos referimos a pessoas ou coisas. Se ocorrer uma mudança em sua hierarquia, porém, ou se uma determinada imagem-ideia for ameaçada de extinção, todo nosso universo se prejudicará (Moscovici, 2009, p. 38).
\end{abstract}

A ontologia das representaçóes sociais, especialmente, como demonstrado na segunda parte do artigo, ilumina o que acabou de ser lido na citação. Ficou demonstrado que os diversos teóricos estudados e adotados por Moscovici (2009) indicam que, a partir da História e da Antropologia, essas representações sociais são entidades sociais. Elas têm vida própria e comunicam-se entre elas. Se o conceito de representação atravessa tantos domínios de conhecimento, 
da História à Antropologia e à Linguística, "Ele é sempre e em todo lugar uma questão de compreensão das formas das práticas de conhecimento e de conhecimento prático que cimentam nossas vidas sociais como existências comuns" (Moscovici, 2009, p. 217). Entretanto é possível compreender mais claramente a ontologia das representações sociais, pela entrevista que Moscovici (2009) concedeu a Marková, que se encontra ao fim da obra Representaçôes sociais, ao compará-las às atitudes. A citação a seguir mostra, por um lado, o que constitui a representação social e, por outro, a diferença entre esta e as atitudes.

\begin{abstract}
Nossas representações são também instituições que nós partilhamos e que existem antes de nós termos nascido dentro delas; nós formamos novas representaçóes a partir das anteriores. As atitudes não expressam conhecimento como tal, mas uma relação com certeza e incerteza, crenças ou descrenças, em relação a esse conhecimento. Pode-se falar também sobre uma atitude em relação a um objeto, uma pessoa, um grupo e assim por diante. Contudo, no que diz respeito a entidades sociais, essas são as entidades representadas (Moscovici, 2009, p. 319).
\end{abstract}

O que dizer dessas palavras de Moscovici (2009)? Primeiramente, ele indica que o ser humano é capaz de ter atitude diante de uma representação social. Porém a representação social seria, por assim dizer, a coisa em si, a entidade real, ontologicamente existente. Pode-se dizer que a atitude participa na seleção e estruturação de conteúdos de representações sociais. Contudo não se pode isolar essa dimensão das demais (Souza Filho, 2004, p. 119). Nesse sentido, é bom lembrar, continua o autor, a observação feita por Moscovici (2012) das

Relaçôes entre atitude e informação "objetiva" da psicanálise entre operários franceses da década de 1950, que possuíam grau de informação baixo, mas mantinham atitude mais favorável; contrariamente aos intelectuais de esquerda, que tinham mais informaçōes e menos favorabilidade em relação à atitude.

\title{
Em outras palavras:
}

Elas (representações sociais) "são", de fato, mas elas não podem ser tocadas. Elas existem, mas não se deixam ver. Elas possuem determinada concretude, mas não podem ser delimitadas, medidas, desenhadas. Elas parecem ser vistas; influenciam, sem que as identifiquemos claramente (Guareschi, 2000, pp. 249-250).

As representações sociais, como uma das áreas da Psicologia Social, levam em conta o significado do afeto, da atividade simbólica, atividade psíquica, cognitiva e os estímulos produzidos pelo ser humano. As representações sociais resultam desse processo simbólico e cognitivo como forma de comunicação por meio da conduta das pessoas. Por isso a Psicologia Social procura "estudar tais 
representações, suas propriedades, suas origens e seu impacto" (Moscovici, 2009, p. 41). Toda representação é representação de alguém, tanto quanto é de alguma coisa. Logo, as representações sociais são sempre circunscritas a um grupo de pessoas que compartilham um saber entre si. É nesse contexto que se poderia dizer que a Psicologia Social "é a ciência dos fenômenos de ideologias (cognições e representações sociais) e dos fenômenos de comunicação" (Moscovici, 2008, p. 7). A representação social não consiste em produzir um conhecimento sobre o sujeito, mas procura saber qual é o conhecimento do sujeito sobre determinado objeto. Daí o dizer que "as representações sociais são entidades quase tangíveis, circulam, se cruzam e se cristalizam continuamente através da fala, dos gestos, do encontro no universo cotidiano" (Moscovici, 2012, p. 39). Para concluir,

Lembremos a proposição teórica de que uma representação social é sempre de alguém (o sujeito) e de alguma coisa (o objeto). Não podemos falar em representação de alguma coisa sem especificar o sujeito - a população ou o conjunto social - que mantém tal representação (Sá, 1998, p. 24).

\section{CONSIDERAÇÕES FINAIS}

O status ontológico revela que as representações sociais têm seus próprios fundamentos filosóficos que as constituem como uma teoria dentro da Psicologia Social. Significa que as representações sociais têm uma origem e uma identidade. Essa origem e identidade mostram que Moscovici recorreu a distintos pensadores em vista da criação do status das representações sociais. Entre esses pensadores, estudamos os seguintes: Durkheim, Lévy-Bruhl, Piaget e Freud. Foi explicado que a formulação do conceito de "representações sociais" foi inspirada nas "representações coletivas", de Durkheim. Moscovici preservou o conceito de "representação" e substituiu o conceito "coletivo", de conotação mais cultural, estática e positiva, pelo conceito de "social". É daí que vem o conceito de representações sociais. Moscovici fez uso também dos estudos de Lévy-Bruhl que, por sua vez, afirmou poder haver diferentes tipos de saber numa mesma sociedade. Se numa mesma sociedade é possível existirem várias formas de pensar, significa, então, que as representações sociais são entidades sociais dinâmicas. Com base na interpretação dos escritos de Lévy-Bruhl, Moscovici mostrou que o conhecimento popular é, para as representaçôes sociais, uma importante fonte de estudo. É nesse contexto que fala Moscovici do significado de polifasia cognitiva: o pensamento social é constituído de uma pluralidade de modos de reflexão. A polifasia cognitiva revela as diferentes formas de reflexão numa mesma sociedade e cultura. 
$\mathrm{Na}$ sequência, vimos que Moscovici encontrou, nas pesquisas de Piaget, um suporte teórico para mostrar que as representações sociais são realidades sociais perpassadas por processos cognitivos. Isso quer dizer que o legado de Piaget mostra a especificidade das representaçôes sociais em termos psíquicos. Foi em Piaget que Moscovici encontrou a conceituação de representação, a investigação do senso comum, a preocupação com a mudança e desenvolvimento no universo da criança. Pelas descobertas de Piaget, Moscovici encontrou a noção de representação plenamente elaborada. A leitura de Freud mostrou a Moscovici que os processos inconscientes estão presentes na produção dos saberes sociais. Uma vez que os processos psíquicos são, em si mesmos, inconscientes, quer dizer que eles apontam para o significado do simbólico. As descobertas de Freud na área da sexualidade infantil revelaram o modo como as crianças constroem a "teoria" da sexualidade, especialmente por meio das lendas e contos de fadas. A partir de Freud, a sexualidade foi compreendida por Moscovici como processo de construção mental como objeto das primeiras experiências das crianças, o que se estenderia à vida adulta. $\mathrm{O}$ status ontológico das representaçôes sociais encontra fundamentos nos aspectos sociológicos, antropológicos, cognitivos e psicanalíticos. Isso permite afirmar que as representações sociais são esse legado teórico desses autores que Moscovici sistematizou. Porém as representações sociais não são só ideias e conceitos, mas, sobretudo, práticas vivenciais que se dão por meio da comunicação. 


\section{REFERÊNCIAS}

Abbagnano, N. (1982). Dicionário de Filosofia. São Paulo: Mestre Jou.

Aristóteles. (2006). Metafísica. Bauru: Edipro.

Durkheim, E. (2003). As formas elementares da vida religiosa. São Paulo: Martins Fontes.

Freud, S. (1905/1996). Três ensaios sobre a teoria da sexualidade. In J. Salomão (Trad.), Edição standard das obras psicológicas completas de Sigmund Freud (Vol. 7, pp. 119-231). Rio de Janeiro: Imago, 1996. (Publicado originalmente em 1905).

Gil, A. C. (2011). Métodos e técnicas de pesquisa social. São Paulo: Atlas.

Guareschi, P. A. (1996). Representações sociais: alguns comentários oportunos. Coletâneas da ANPEPP. (Vol. 10, pp. 9-35). Florianópolis: Imprensa Universitária, Universidade Federal de Santa Catarina.

Guareschi, P.A. (2000). Representações sociais: avanços teóricos e epistemológicos. Temas em Psicologia, 8(3), 249-256.

Guareschi, P. A. (2007). Psicologia social e representações sociais: avanços e novas articulações. In M. Verosene, \& P. A. Guareschi (Orgs.), Psicologia do cotidiano: representaçôes sociais em ação. (pp. 17-40). Petrópolis: Vozes.

Guareschi, P. A. (2011). "Sem dinheiro não há salvação": ancorando o bem e o mal entre neopentecostais. In P. A. Guareschi, \& S. Jovchelovitch (Orgs.), Psicologia social: textos em representaçôes sociais. (pp. 153-181). Petrópolis: Vozes.

Jovchelovitch, S. (2011). Os contextos do saber: representaçôes, comunidade e cultura. Petrópolis: Vozes.

Marconi, M. A., \& Lakatos, E. M. (2011). Técnicas de pesquisa: planejamento e execução de pesquisas, amostragem e técnicas de pesquisa, elaboração, análise e interpretação de dados. São Paulo: Atlas.

Marková, I. (2006). Dialogicidade e representaçôes sociais: as dinâmicas da mente. Petrópolis: Vozes.

Moscovici, S. (2001). Das representações coletivas às representações sociais: elementos para uma história. In D. Jodelet (Org.), As representaçôes sociais. (pp. 45-90). Rio de Janeiro: EdUERJ. 
Moscovici, S. (2008). Psychologie sociale: sons la direction de Serge Moscovici. Paris: Puf.

Moscovici, S. (2009). Representaçôes sociais: investigaçôes em psicologia social. Petrópolis: Vozes.

Moscovici, S. (2012). A psicanálise, sua imagem e seu público. Petrópolis: Vozes.

Nóbrega, S. M. (2003). Sobre a teoria das representaçôes sociais. In A. S. P. Moreira, \& J. C. Jesuino (Orgs.), Representaçôes sociais: teoria e prática. (pp. 51-80). João Pessoa: Editora Universitária.

Piaget, J. (1994). O juizo moral na criança. São Paulo: Summus.

Piaget, J. (2007). Epistemologia genética. São Paulo: Martins Fontes.

Rey, F. G. (2012). O social na Psicologia e a Psicologia Social: a emergência do sujeito. Petrópolis: Vozes.

Sá, C. P. (1998). A construção do objeto de pesquisa em representaçôes sociais. Rio de Janeiro: EdUERJ.

Severino, A. J. (2002). Metodologia do trabalho cientifico. São Paulo: Cortez.

Souza Filho, E. A. (2004). A análise de representações sociais. In M. J. Spink (Org.), O conhecimento no cotidiano: as representaçóes sociais na perspectiva da psicologia social. (pp. 109-145). São Paulo: Brasiliense. 